\title{
Voleibol escolar: uma proposta de ensino nas dimensões conceitual, procedimental e atitudinal do conteúdo
}

CDD. 20.ed. 796.017

796.325

\author{
André Luís Rugiero BARROSO* \\ Suraya Cristina DARIDO* \\ *Universidade Estadual \\ de Paulista - Rio Claro.
}

\begin{abstract}
Resumo
0 objetivo deste estudo foi construir, implementar e avaliar uma proposta de ensino do voleibol nas três dimensões do conteúdo: conceitual, procedimental e atitudinal. Para o desenvolvimento da pesquisa foi utilizado o método da pesquisa-ação, sendo realizados oito encontros, havendo a participação de quatro professores. Os resultados obtidos foram discutidos na perspectiva das condições de trabalho, em por que e para que ensinar esporte (voleibol), na técnica esportiva e rendimento, nas dimensões do conteúdo e nas características, expectativas e na participação dos alunos. Verificou-se que em determinadas escolas as condições de trabalho, seja em relação ao espaço físico, ao material disponivel, à desvalorização da Educação Física ou mesmo à desconfiança por parte dos professores de outras áreas e da direção, apresentam-se como obstáculos para o desenvolvimento desse componente curricular. Entretanto, observou-se que os professores participantes conseguiram desenvolver um ensino de qualidade, contribuindo para o redimensionamento da importância da Educação Física no ambiente formal de ensino. Confirmou-se a possibilidade de desenvolvimento de aulas que possam ir além da dimensão procedimental, facilitando a abordagem das dimensões conceituais e atitudinais do voleibol. Além disso, constatou-se uma participação efetiva dos alunos, mas isso somente se deu devido à disposição dos professores em estruturarem de forma apropriada as suas aulas estudando, destinando tempo para elaboração das atividades e oferecendo estratégias diversificadas que estimulassem o envolvimento dos alunos.
\end{abstract}

Unitermos: Educação física; Escola; Pedagogia do esporte; Pesquisa-ação; Voleibol.

\section{Introdução}

O esporte é tratado por vários autores, entre eles Betti (1991), Bracht (2000/2001), Paes (2002), Mesquita (2006), como um fenômeno sociocultural, sendo considerado um patrimônio da humanidade. Historicamente foram criadas diversas modalidades esportivas que sofreram alterações gradativamente até o momento atual.

Ao analisar o surgimento dos esportes modernos, KORSAKAS (2002) afirma que a sua origem se deu no século XIX, acompanhando o desenvolvimento da sociedade capitalista. A autora observa que vários tipos de jogos foram alterados até chegarem ao esporte-espetáculo transformando-se em um produto de consumo para a sociedade.

Entretanto, cabe à comunidade científica e aos profissionais da área compreender que o esporte direcionado para o profissionalismo é apenas uma de suas possibilidades. PAES (2002), por exemplo, sinaliza além do esporte profissional, o esporte dentro do ambiente escolar, o esporte como componente do lazer, o esporte adaptado para pessoas com necessidades especiais. TUBINO (2002) aborda o esporte a partir de três manifestações: esporte-educação, que tem como meta o caráter formativo; esporte-participação, cujas finalidades são o bem-estar e a participação do praticante; esporte-performance, objetivando o rendimento dentro de uma obediência rígida às regras e aos códigos existentes para cada modalidade esportiva.

De acordo com PAES (2002) os profissionais da área ao desenvolverem o esporte devem inicialmente verificar em qual cenário ele ocorrerá, qual o público a ser contemplado, para então definir os objetivos a serem atingidos e estabelecer as estratégias de trabalho. 
É com enfoque na utilização do esporte no ambiente formal de ensino, ou seja, a escola, como se referem Tubino (2002) e PAES $(2002,2006)$ o foco dessa pesquisa, pois se o esporte está presente na vida dos indivíduos, nada mais significante que esteja inserido na escola, mais especificamente no componente curricular Educação Física.

Para o estudo abordou-se uma das manifestações do fenômeno esporte, tratando especificamente da modalidade esportiva voleibol de quadra, que segundo BoJIKIAN (2003) originou-se na divisão de Educação Física da Associação Cristã de Moços em Massachusetts, Estados Unidos, em 1895, com o nome de "minonette", sofrendo evoluçōes e alterações nas regras, até atingir a forma atual de se jogar.

O voleibol é uma modalidade esportiva coletiva apresentando na sua essência o jogo, fator que socioculturalmente motiva e estimula as pessoas, mostrando-se muito favorecido e propício o desenvolvimento da sua prática. Porém, apresenta-se preocupante o ensino da modalidade esportiva voleibol na escola sem um procedimento metodológico apropriado, tendo o objetivo voltado apenas para a assimilação de gestos técnicos. Dessa forma, não ocorre o direcionamento para a reflexão em um contexto mais abrangente, por exemplo, o entendimento da origem e evolução da modalidade esportiva e que atitudes podem ser promovidas durante o seu ensino.

Trabalhar o esporte na escola sem ter como propósito a reflexão do indivíduo, proporciona o surgimento de situaçôes que poderão ocasionar problemas, como a busca incessante de talentos, treinamento esportivo na aula de Educação Física, especialização precoce, exclusão dos menos habilidosos, desinteresse pela prática esportiva, entre outros, sendo a Educação Física idealizada como modelo de esporte de rendimento.

\section{Método}

\section{A escolha do método}

Para desenvolvimento deste estudo optou-se pela utilização do método qualitativo da pesquisa-ação, o qual proporcionou uma intervenção direta no grupo de professores de Educação Física escolar participantes da pesquisa.

THIOLLENT (2003) define a pesquisa-ação como: [...] um tipo de pesquisa social com base empírica que é concebida e realizada em estreita
Baseado em autores como Zabala (1998) e Coll, Pozo, Sarabia e Valls (2000) adotou-se as dimensōes do conteúdo: conceitual, procedimental e atitudinal como referência para desenvolvimento da modalidade esportiva voleibol nas aulas de Educação Física escolar do Ensino Fundamental II (séries finais do ensino fundamental). Esta classificação, baseada em Coll et al. (2000) corresponde às seguintes questões: "o que se deve saber?" (dimensão conceitual), "o que se deve saber fazer?" (dimensão procedimental), e "como se deve ser?" (dimensão atitudinal).

Encontra-se na literatura estudos contemplando o ensino do voleibol no ambiente escolar, como QUADROS Júnior, QuAdros e Gordia (2007), CAMPOS (2006), Lemos (2004); entretanto, esta pesquisa apresenta a perspectiva de uma inter-relação entre o ensino desta modalidade esportiva e as dimensóes do conteúdo.

Entendeu-se que, ao se elaborar e aplicar aulas do conteúdo esporte ou dos demais conteúdos pertencentes à área de conhecimento da Educação Física escolar, tendo como eixo norteador as três dimensões, conforme defendido, por exemplo, pelos PCN's (BrasIL,1998) e DARIDO e RANGEL (2005), favorece o desenvolvimento do processo de ensino e aprendizagem, com o propósito de uma formação de maior qualidade dos alunos.

A ideia é que sejam estruturadas formas apropriadas para aplicação da modalidade voleibol na perspectiva da dimensão procedimental, esta que historicamente foi e é muito adotada na prática pedagógica dos professores da área; como também, possam ser desenvolvidas atividades nas perspectivas das dimensões conceitual e atitudinal.

Sendo assim, o objetivo deste trabalho foi construir, implementar e avaliar uma proposta de ensino do voleibol nas três dimensões do conteúdo: conceitual, procedimental e atitudinal, e identificar as possibilidades e dificuldades do desenvolvimento desta proposta. associação com uma ação ou com a resolução de um problema coletivo e no qual os pesquisadores e os participantes representativos da situação ou do problema estão envolvidos de modo cooperativo ou participativo (p.14).

O autor ressalta que, nesse método, há necessidade de um inter-relacionamento entre o pesquisador e as pessoas participantes do estudo, pois ele atua ativamente na perspectiva de resolução dos problemas identificados. 
ANDRÉ (1995) destaca determinados traços essenciais para o processo de pesquisa-ação: "análise, coleta de dados e conceituação dos problemas; planejamento da ação, execução e nova coleta de dados para avaliá-la; repetição desse ciclo de atividades" (p.31).

Thiollent (2003) apresenta dois objetivos da pesquisa-ação na qual há necessidade de um relacionamento entre eles, garantindo a especificidade do método: o objetivo prático, que tem o intuito de resolução dos problemas, sendo este o eixo principal da pesquisa e o objetivo de conhecimento ocorrendo a possibilidade de uma melhor obtenção das informações, caracterizando-se de forma clara e determinante.

Entendeu-se que o método da pesquisa-ação foi apropriado para esta pesquisa, entretanto ressalta-se que o mesmo não trabalha com dados quantitativos. Portanto, na análise dos resultados mostrou-se necessária uma subjetividade por parte dos pesquisadores para desenvolvimento do estudo.

\section{Formação do grupo}

Estruturou-se o grupo com a participação de quatro professores. Entre os integrantes, apenas dois eram conhecidos do professor pesquisador; os outros dois foram indicados por uma Professora que trabalha com o professor pesquisador e por um dos membros do Laboratório de Estudos e Trabalhos Pedagógicos em Educação Física (LETPEF) ${ }^{1}$.

Válido ressaltar que a escolha dos professores participantes foi intencional, levando-se em conta as possibilidades de participação nas reuniōes, o local de trabalho próximo ao pesquisador e o fato dos professores mostrarem interesse em melhorar a sua própria prática. Esse perfil acabou agrupando professores em início de carreira docente.

Outro fator era que os professores participantes não se conheciam previamente. $\mathrm{O}$ professor pesquisador fez contato pelo telefone e e-mail com esses professores para fazer o convite, explicar quais os objetivos da pesquisa e como seria o desenvolvimento dos trabalhos.

\section{Participantes}

A Professora 1 formou-se pela Pontifícia Universidade Católica de Campinas (PUCCAMP) no ano de 1999. Fez duas especializações, a primeira em Educação Física Escolar na FMU em 2001 e a segunda em Pedagogia do Esporte Escolar na UNICAMP em 2006. Já cursou disciplina como aluna especial da pós-graduação na UNICAMP, e na ocasião deste estudo, cursava uma disciplina também como aluna especial na mesma instituição. Trabalha no Ensino Fundamental II desde 2002 e atua na escola da instituição SESI no município de Valinhos desde 2005.

A Professora 2 possui formação em Letras na UNIFEOB, em São João da Boa Vista. Nesse mesmo município cursou Educação Física na UNIFAI, no ano de 2006. Foi aprovada no concurso para professores do Estado de São Paulo no final de 2006, assumiu o cargo na escola no início de 2007, portanto, havia quatro meses que trabalhava no Ensino Fundamental II em uma escola do município de Campinas.

A Professora 3 formou-se pela Pontifícia Universidade Católica de Campinas (PUCCAMP) em 2006. Iniciou em 2007 um curso de especialização, porém não o concluiu. Foi aprovada em um concurso para professores no município de Vinhedo, sendo contratada em caráter de Professora eventual, tendo início do contrato em março de 2007 e término deste em dezembro de 2007. Portanto, atuava no Ensino Fundamental II há três meses.

O Professor 4 completou a graduação na habilitação de licenciatura nas Faculdades Metropolitanas de Campinas em 2005. Em 2006, nessa mesma instituição de ensino formou-se na habilitação de graduação (bacharelado). Nesse ano foi contratado na escola, local onde havia feito estágio durante o período da faculdade, sendo uma escola privada de ensino fundamental e médio.

Esclareceu-se aos professores que o trabalho não consistia em realizar uma avaliação da atuação profissional, mas sim construção, implantação e avaliação de uma proposta de ensino do voleibol escolar, verificando as suas possibilidades e dificuldades, sempre respeitando a realidade de cada professor participante.

Este trabalho é fruto de uma dissertação de mestrado e, durante a qualificação, a banca examinadora não exigiu a submissão do estudo ao comitê de ética em pesquisa. Desta forma o estudo foi desenvolvido com o consentimento livre dos indivíduos envolvidos e, para tanto, foram esclarecidos sobre os riscos e o direito de desistir a qualquer momento. Todos os participantes concordaram com a apresentação dos dados em publicaçôes, sendo resguardado o sigilo pessoal.

\section{Instrumentos de coleta das informações}

Os oito encontros foram realizados nas salas de estudos das bibliotecas da Faculdade de Educação Física da UNICAMP, da Faculdade de Educação Física da PUCCAMP e do Colégio Progresso.

Eles duraram entre uma hora e duas horas e 30 minutos e essa variação se deu devido aos 
compromissos particulares dos participantes da pesquisa e do tema a ser desenvolvido. Como exemplo, para o quinto e oitavo encontros necessitou-se de um tempo maior de reunião devido, respectivamente, à elaboração de atividades e à avaliação e ao fechamento dos trabalhos. Porém, o tempo de duração de cada encontro era previsto e combinado previamente com os professores.

Todos os encontros foram gravados em uma máquina filmadora Sony Handycam (modelo DCR-HC32) e transcritos na íntegra pelo professor pesquisador, por meio de digitação no computador em programa Word 2000, após a realização de cada encontro.

Para atingir os objetivos da pesquisa foi realizada também entrevista semi-estruturada inicial e final com os participantes do estudo. Esses dados permitiram aprofundar as interrogativas e esclarecer os problemas observados.

Os temas geradores da entrevista semi-estruturada inicial estiveram pautados nos dados gerais dos participantes (nome, instituição e ano da graduação, instituição e ano da pós-graduação, tempo de atuação no ensino fundamental II, tempo de atuação na escola de aplicação da pesquisa); nos espaços, materiais e conhecimentos prévios e experiências que os professores tinham em relação ao voleibol, quais as dificuldades eles enfrentam em ministrar as aulas na escola e quais as suas propostas para os encontros.

$\mathrm{Na}$ entrevista final buscou-se identificar as dificuldades que os professores enfrentaram na implementação do voleibol nas três dimensões do conteúdo, o que identificavam que os alunos haviam aprendido nas aulas e qual era a avaliação geral do trabalho realizado. $\mathrm{Na}$ transcrição das respostas dos professores respeitou-se o discurso oral e a gramaticalidade, de forma a garantir a preservação do

\section{Resultados e discussão}

A seguir serão apresentados os resultados alcançados empregando o modelo da triangulação, no qual constam informações obtidas na bibliografia específica, o que foi discutido nas reunióes, o que foi observado na prática pedagógica das Professoras e o que se apreendeu por meio das entrevistas. Os resultados dessas fontes de informação ou, como prefere Yin (2001), fontes de evidência, foram confrontados no sentido de identificar a coerência entre o que se faz, o que se diz fazer e o que deveria ser feito. conteúdo semântico das respostas dos entrevistados. Para garantir a fidelidade da transcrição realizou-se o procedimento sistemático de audição e confirmação de pequenos segmentos de texto.

Os professores participantes definiram as seguintes turmas para aplicação das aulas, sendo que as Professoras 1 e 3 têm três aulas semanais e os Professores 2 e 4 apenas duas: Professora 1 - uma turma de $6^{\mathrm{a}}$ série; Professora 2 - uma turma de $6^{\mathrm{a}}$ série; Professora 3 - cinco turmas de $5^{\text {a }}$ série e cinco turmas de $6^{\mathrm{a}}$ série; Professor 4 - duas turmas de $5^{\mathrm{a}}$ série.

Apesar de o Ensino Fundamental II englobar nessas escolas de $5^{\mathrm{a}}$ a $8^{\mathrm{a}}$ séries, a aplicação das aulas direcionou-se para as turmas de $5^{\mathrm{a}}$ e $6^{\mathrm{a}}$ séries. Isso se deu devido a serem essas as turmas atuais para as quais os professores ministram aulas e também por opção de alguns desses professores.

Entendeu-se que seria importante para o desenvolvimento da pesquisa haver contato direto com alguns professores durante a sua prática pedagógica; sendo assim, o professor pesquisador observou seis aulas de três turmas de $5^{\text {a }}$ séries da Professora 3 e aplicou juntamente com a Professora 2 oito aulas para uma turma de $6^{\mathrm{a}}$ série. Optou-se por essas duas professoras pelo fato de trabalharem em escolas públicas, pois a Professora 3 já estava desenvolvendo o conteúdo voleibol nas suas aulas e a Professora 2 apresentou certa insegurança para a aplicação desta proposta de trabalho.

As observações das aulas das professoras possibilitaram um contato estreito do pesquisador com o fenômeno pesquisado. Dessa forma, pode-se acompanhar todas as suas ações, falas, estratégias, relacionamentos, enfim todas as decisões para o desenvolvimento do processo de ensino e aprendizagem do voleibol nas três dimensões do conteúdo.

A partir da triangulação dos dados chegou-se às seguintes categorias: condiçôes de trabalho, por que e para que ensinar voleibol, técnica esportiva e rendimento, dimensões do conteúdo, alunos - características, expectativas e participação. Esses tópicos nortearam o desenvolvimento dos trabalhos com os professores participantes.

Destaca-se que, apesar de ocorrer uma separação dessas categorias, elas apresentaram-se interligadas em muitas ocasiōes; entretanto, o objetivo dessa separação foi caracterizar com maior evidência cada uma delas. 


\section{Categoria: condições de trabalho}

Esta categoria aborda as condiçōes para desenvolvimento de trabalho dos professores nos seus ambientes escolares tratando de aspectos referentes à relação do professor com as pessoas que exercem os cargos administrativos, relação com outros professores de Educação Física da própria escola e com os professores dos demais componentes curriculares, como também, a estrutura física para o desenvolvimento das aulas e o material disponível.

Devido à diversidade de informações e discussōes realizadas nesta categoria, optou-se por dividi-la em três subcategorias: espaço físico e materiais, "status" do componente curricular e trabalho coletivo.

\section{Espaço físico e materiais}

Fazendo uma análise dos primeiros posicionamentos dos professores quando questionados sobre qual o espaço e o material que possuem para as aulas, apresentou-se como característica a queixa das professoras de escolas públicas (Professoras 2 e 3 ) em relação à deficiência do espaço físico e à pouca quantidade de materiais para o desenvolvimento das aulas. Verificamse problemas dessa natureza em outros trabalhos, como o estudo de Bracht, Caparroz, Della Fonte, Frade, Paiva e Pires (2003), em que os autores também fizeram uso do método da pesquisa-ação, alertando para o fato de ser comum a ocorrência de instalaçôes e materiais precários em escolas públicas.

Observou-se as respostas direcionadas para uma visão mais tradicional da Educação Física escolar, pontuando apenas os espaços de quadra e os materiais considerados para atividades práticas. Considera-se essas propostas como tradicionais, pois elas vislumbram apenas o ensino das técnicas e táticas esportivas na dimensão procedimental, em espaços determinados como quadras e ginásios. Ao contrário, são consideradas propostas renovadoras, aquelas que incluem diversos conteúdos da cultura corporal, que aprofundam o seu conhecimento e variam os espaços destinados às aulas de Educação Física, quando incluem sala de computação, campos de terra, sala de aula, etc. (DARIDO \& RANGEL, 2005).

Somente a Professora 1 citou a utilização de outros espaços, porém, surgindo a partir de uma dificuldade logística da escola para a composição das aulas de Educação Física.

Não se questiona a quadra como espaço de aula deste componente curricular, apenas levantando a possibilidade de realizações de aulas em outros ambientes, da mesma forma que poderiam ser citados outros tipos de materiais. Entende-se que isso se dá essencialmente pelo conceito formado deste componente curricular ao longo dos anos, no qual o espaço para as aulas é exclusivamente a quadra e estas aulas privilegiam apenas a execução dos movimentos.

Foi positivo o fato de durante a aplicação das aulas da pesquisa os professores utilizarem outros espaços na escola, entre eles a própria sala de aula, a sala de vídeo/ dvd, embaixo de árvores, etc. Também a exploração de outros materiais, seja especificamente pelos professores - o Professor 4 fez uso de projeçôes no computador para explicar a origem e a evolução do voleibol; a Professora 1 realizou a filmagem dos alunos na aula para posteriormente discutir algumas atitudes perante os colegas; a Professora 2 juntamente com o professor pesquisador, mostrou uma reportagem de um programa de televisão sobre o voleibol sentado, discutindo o oferecimento da modalidade a todos, independentemente de facilidades ou dificuldades nas habilidades motoras e o respeito às diferenças; a Professora 3 filmou a apresentação dos grupos do teatro e exibiu para os alunos -, seja no caso dos alunos - a confecção da maquete da quadra de voleibol das turmas da Professora 3 e do Professor 4, com a utilização de canetas hidrográficas, caixa de sapato, tintas para pintura em papéis, entre outros materiais; a utilização de cartolinas para confecção de um quadro com regras antigas do voleibol e as regras atuais pelos alunos da Professora 2; ou mesmo a elaboração de textos para montagem do teatro nas turmas da Professora 3.

Assim, os encontros possibilitaram a ampliação da concepção de espaço de aula para a Educação Física escolar.

\section{"Status" do componente curricular}

As Professoras 2 e 3, pelo fato de serem recentemente formadas e aprovadas em concursos públicos, tendo entrado em suas respectivas unidades escolares há pouco tempo, passaram por situações de falta de confiança e, até mesmo, desprezo profissional.

[...] eu e a outra professora da manhã estamos numa dificuldade muito grande, porque nós somos substitutas de outras professoras, que tiraram licença por algum motivo, mas não se desligaram da escola totalmente. Ela aparece do nada e fala assim: isso aqui vocês não vão usar, vocês usam essas bolas, quando vocês verem que não dá mais pra usar, vocês remendam, porque precisam durar muito essas bolas. Então nós somos controladas o tempo inteirinho por outra professora, entendeu? (Professora 3). 
Percebe-se neste caso a falta de autonomia da Professora 3 em relação à sua prática pedagógica, inclusive tal fato é reforçado pela direção da escola. Essa mesma Professora também relatou que foi questionada pelo coordenador da escola sobre o porquê das aulas de Educação Física serem realizadas com meninas e meninos juntos, pois, segundo ele, pelo fato dos meninos serem mais fortes, poderiam machucar as meninas, portanto, as atividades deveriam ser realizadas separadamente.

SOUZA JúNIOR (2004) em seu estudo destaca que a diferença no desenvolvimento das habilidades motoras entre meninos e meninas está mais relacionada à construção cultural do que propriamente dependente dos aspectos biológicos. Conforme BeTti (1991) e DARIDO e RANGEL (2005) a realização de aulas separadas para meninos e meninas remete a uma Educação Física esportivista, idealizada na década de 70, cujos objetivos se voltavam para a aptidão física e a detecção de talentos esportivos.

$\mathrm{O}$ pesquisador foi testemunha de um episódio infeliz ocorrido com a Professora 2. Esta havia reservado previamente a sala de tv para exibir um material com o dvd; foram até a sala, juntamente com os alunos, e após a acomodação de todos, chegou a professora de geografia, argumentando que utilizaria a sala porque os alunos iriam apresentar um trabalho. Mesmo a professora 2 tendo feito a reserva, percebeu-se o desrespeito da professora de geografia, tanto com a colega de profissão e os alunos, como com a própria Educação Física.

Esse tipo de acontecimento é contrário às ideias de TOURAINE (1998) ao defender uma escola democrática, valorizando a formação do sujeito, tendo que haver para isso uma qualidade no relacionamento entre as pessoas integrantes do núcleo escolar: alunos, professores, coordenação, direção, demais funcionários.

O Professor 4 foi questionado sobre a reserva que havia feito na sala de audiovisual para projeção de slides referentes ao voleibol, pois a coordenação da escola gostaria de entender por que a aula de Educação Física não seria realizada na quadra, como se este fosse o único espaço destinado ao componente curricular.

Outro aspecto levantado pela Professora 3 é o fato de alguns professores quererem punir os alunos considerados indisciplinados na sala de aula com a não-participação nas aulas de Educação Física. Isso remete a duas interpretações em relação ao conceito da Educação Física para tais profissionais: a primeira retrata a desvalorização do componente curricular, como se não houvesse nenhum conhecimento substancial para a aprendizagem do aluno; a segunda é de que a Educação Física é um momento de mero lazer para os alunos podendo escolher o que fazer nesse horário.

\section{Trabalho coletivo}

Chamou à atenção a falta de estruturação da Educação Física em uma mesma instituição de ensino. Por meio de relatos dos professores percebeuse uma desarticulação entre os profissionais da área não possibilitando a construção de objetivos comuns entre as diversas séries de ensino e, consequentemente, entende-se que não deve haver uma inter-relação com o projeto político pedagógico da escola.

Um aspecto positivo foi o fato de os professores durante a aplicação das aulas, conseguirem certo rompimento na visão de que a Educação Física não tem o mesmo valor dos demais componentes curriculares. Obviamente essa mudança levará algum tempo para ser concretizada totalmente, porém começa a ser construída pelas ações dos próprios professores, ao valorizarem os conteúdos pertencentes à área de conhecimento, ao planejarem a sua prática pedagógica, ao demonstrarem o trabalho que pode ser realizado, inclusive envolvendo os demais professores nos projetos interdisciplinares.

Isso aconteceu com a Professora 3, pois ela trabalhou a origem da modalidade esportiva voleibol, mas não apenas transmitindo informações aos seus alunos referentes a nomes, datas, locais, e sim, aplicando uma estratégia que propiciasse a participação efetiva dos alunos no processo de ensino e aprendizagem e envolvesse professores de outras áreas no desenvolvimento desse conteúdo. Para tanto, sugeriu a estruturação e encenação de um teatro com as turmas de $5^{\mathrm{a}}$ série tendo como tema a origem e a evolução do voleibol.

No seu relato de experiência sobre a participação da Educação Física escolar no Projeto Político Pedagógico, VenÂncio (2005) destaca a importância do trabalho coletivo, fazendo com que esse componente curricular mantivesse a sua especificidade e, ao mesmo tempo, fosse integrado com os demais componentes. Segundo a autora para que haja o desenvolvimento de um trabalho coletivo torna-se necessário que as pessoas envolvidas estipulem e percorram os mesmos caminhos, a fim de alcançarem os objetivos almejados.

DARIDO e RANGEL (2005) defendem a estruturação de projetos no ambiente escolar para possibilitar uma melhor aprendizagem. O projeto desenvolvido pela Professora 3 conceitua-se como interdisciplinar, no qual, conforme as autoras, há necessidade de os alunos buscarem o conhecimento em outros componentes curriculares para entendimento do que está sendo desenvolvido. 
Um outro exemplo positivo para valorização e maior participação da Educação Física no ambiente escolar foi realizado pelo Professor 4 com o envolvimento da Educação Física em eventos da escola, tratando-se da amostra cultural na sua respectiva instituição de ensino: "Esse ano vai ter, em setembro vai ter amostra cultural, a Educação Física nunca apresenta nada lá. Eu falei pro coordenador, vamos colocar alguma coisa esse ano, a gente deixa um espaço pra apresentar alguma coisa” (Professor 4).

Apesar de inúmeras dificuldades apresentadas pelos professores participantes em relação à estrutura da escola, como o material disponível para a realização das aulas, o relacionamento com os demais professores, a coordenação e a direção da escola, observou-se que eles conseguiram muitos avanços, principalmente na defesa de uma Educação Física que pode e deve contribuir para a formação dos alunos e que não seja avaliada como um componente de menor importância no ambiente formal de ensino.

\section{Categoria: por que e para que ensinar voleibol?}

As questōes por que e para que ensinar voleibol são referentes aos objetivos da Educação Física no ambiente escolar. Em determinados momentos realizou-se uma discussão mais profunda com o grupo de professores sobre esses aspectos, porém em todos os encontros essas questôes permeavam os debates, pois era necessário ter clareza do que se pretendia ao ensinar esporte na escola.

Procurou-se discutir o conteúdo esporte como um meio e não tê-lo como um fim em si mesmo, pois historicamente isto já ocorreu quando SOARES, TAfFarel, Varjal, Castellani Filho, Escobar e Bracht (1992) mostram a utilização desse conteúdo com regras e normas relacionadas ao esporte desenvolvido em federações e confederações, tendo o objetivo direcionado para a aptidão física e a detecção de talentos.

Em seguida realizou-se o debate procurando estabelecer os objetivos de se trabalhar o voleibol ou qualquer outra modalidade esportiva nas aulas de Educação Física. Apontou-se para a possibilidade de se ter um conceito mais significativo, dessa forma buscamos as ideias de GaLVÃo, Rodrigues e SancheS NETO (2005) ao definirem que "o objetivo principal da Educação Física escola é introduzir e integrar os alunos na Cultura Corporal de Movimento" (p.34).

Após as discussões chegou-se à conclusão de que os alunos têm o direito de conhecer o que foi construído historicamente, obviamente sabe-se que só no esporte existe um número acentuado de modalidades esportivas, portanto, o professor não conseguirá apresentar todas, porém, mostra-se possível uma maior diversificação, tanto no número de modalidades, quanto nos temas a serem abordados em cada uma delas.

Na questão para que ensinar voleibol direcionouse a atenção para o que se pretendia ao ensinar esse conteúdo no âmbito escolar. Percebeu-se uma visão pontual da Professora 3, sendo determinante nas colocações ao abordar essa questão:

Autonomia. Eu acho que eles precisam ser preparados pra vida em sociedade, eles vão ter um momento que se desvincular da escola, de um professor que esteja auxiliando ele o tempo todo. Seja uma pessoa curiosa, crítica, aprender a viver em grupo, saber que ele não vai conseguir as coisas sozinho, que ele precisa ajudar a construir alguma coisa também (Professora 3).

Há concordância com os PCN's (BRASIL,1998) quando este documento defende a Educação direcionada para uma apropriada formação cidadã. Cidadania esta que, segundo Palma FILHo (1998) não apresenta um conceito universal, sendo dependente das mudanças ocorridas na história e das diferentes sociedades político-econômicas existentes.

Nesse entendimento a Educação Física, juntamente com os demais componentes curriculares, deve propiciar a construção de uma formação que possibilite o exercício da cidadania. Ressalta-se que Covre (1999) e PINSKY (2001) relacionam a cidadania aos direitos, deveres e atitudes referentes aos cidadãos, almejando uma melhora de vida coletiva na sociedade à qual pertencem.

BetTi (1999) ao defender uma Educação Física direcionada à cidadania, destaca que não é o fato de a Educação Física constar na legislação como componente escolar que garantirá a todos terem acesso ao seu conteúdo. Ou seja, para o autor dependerá do professor se realmente os alunos entrarão em contato com o conhecimento da área, pois ela pode estar na grade curricular e ser destinada a apenas determinados alunos e/ou apresentar conteúdos reduzidos, impossibilitando que na prática escolar a Educação Física aconteça de uma forma que permita ao aluno conquistar a sua cidadania.

Entende-se que para o favorecimento da autonomia e da formação cidadã é necessária a realização de constantes atividades direcionadas nesse sentido. Com isso, ressalta-se a atividade realizada pela Professora 1, quando dividiu a turma em dois grupos e colocou em pauta a discussão sobre o caso da dispensa do levantador da seleção brasileira de voleibol, dias antes da realização dos Jogos Pan-Americanos na cidade do Rio de Janeiro. 
A Professora trouxe um episódio em evidência na mídia para ser discutido na sala de aula, fazendo com que os alunos colocassem as suas opiniōes, ouvissem os posicionamentos de seus colegas, propiciando um debate durante a aula de Educação Física.

Destacam-se nesta categoria da pesquisa as relações que foram possíveis de serem realizadas, principalmente ao discutir as dimensões do conteúdo, pois se a proposta for de uma Educação Física direcionada à formação cidadã, torna-se necessária a estruturação de estratégias que trabalhem, além do ensino de habilidades motoras, os aspectos referentes aos conceitos, valores e atitudes envolvidos no conteúdo esporte.

\section{Categoria: técnica esportiva e rendimento}

Quando foi solicitado aos professores que se posicionassem sobre a utilização da técnica nas aulas de Educação Física houve um contraponto, tendo posicionamentos a favor e contra. Com isso percebeu-se a necessidade de realizar um breve resgate histórico referente aos objetivos do esporte neste componente curricular.

$\mathrm{Na}$ década de 70 com a Educação Física esportivista eram valorizados os alunos que executavam corretamente as técnicas das modalidades apresentadas pelo professor. Na verdade, a única forma aceitável para realização dos movimentos era executando a denominada técnica esportiva, existindo uma predeterminação da padronização dos movimentos.

BRACHT (2000/2001), um dos idealizadores da pedagogia crítica em Educação Física, alerta para o fato de que a crítica à técnica esportiva não aponta para a sua retirada das aulas, mas sim a sua vinculação a novos objetivos educacionais a partir da ressignificação do próprio esporte.

COSTA e NASCIMENTO (2004), além de ressaltarem a importância da técnica, destacam a necessidade de metodologias apropriadas para o seu ensino, ao tratarem do esporte como conteúdo da Educação Física escolar.

MAUSS (1974) ao tratar de movimentos humanos conceitua o termo técnica corporal como sendo "as maneiras como os homens, sociedade por sociedade e de maneira tradicional sabem servir-se de seus corpos" (p.211).

$\mathrm{O}$ autor defende a ideia de que cada povo ou sociedade apresentará as suas técnicas corporais próprias para os mesmos objetivos de movimentos. Entretanto, o autor ressalta que essas técnicas podem sofrer influências como o andar das moças francesas assemelhando-se ao das moças norte-americanas durante o período da expansão do cinema.
No caso da modalidade voleibol isso também é característico, pois nas primeiras décadas do século XX, logo após o seu surgimento em 1895 (BOJIKIAN, 2003), o jogo desenvolvia-se realizando os fundamentos de saque por baixo e toque. $\mathrm{O}$ fundamento manchete só foi criado a partir da década de 60 pela escola asiática (Japão, China, Coréia). O surgimento desse movimento ocorreu em resposta ao movimento da cortada, criada anteriormente pela considerada escola do Leste Europeu (União Soviética, Polônia, Tchecoslováquia) (BızzocchI, 2004).

Rodrigues e DARIDo (2008) no estudo sobre a visão de tendências pedagógicas sócio-culturais da Educação Física destacam que a técnica é um elemento da cultura corporal de movimento; assim, deve ser preservada na prática pedagógica do professor, pois se apresenta como um produto da dinâmica cultural.

Entende-se portanto que, o problema não seja a técnica, mas sim o uso que se faz dela. A principal diferença em relação ao período esportivista dá-se no peso que o professor estipulará para esta técnica, pois naquele período somente eram valorizados os alunos que as aprendiam com certo grau de perfeição. Defende-se a apresentação dessa técnica aos alunos, deixando claros os seus objetivos, porém não desvalorizando a execução da mesma se vier a ocorrer de forma imprecisa; também não deve ser excluída a possibilidade de execução de diferentes formas de movimentos.

Após discussōes envolvendo o assunto observouse um melhor entendimento sobre o termo técnica esportiva, as possibilidades de ser trabalhada nas aulas e qual deve ser o nível de exigência de execução durante o processo de aprendizagem.

Quando abordado o termo rendimento, levantando a questão se ele deve estar presente nas aulas de Educação Física, os professores já no primeiro momento começaram a se posicionar sobre as interpretações dessa palavra, conforme colocação feita pela Professora 1: "O melhor de todos ou dar o melhor de si?"

BRACHT (2000/2001) chama a atenção para mais uma interpretação equivocada sobre a questão do rendimento, criando uma contraposição: "os do rendimento $\mathrm{x}$ os do lúdico (os do formal $\mathrm{x}$ os do informal; os do alto nível $\mathrm{x}$ os do esporte para todos etc.)" (p.17). Segundo o autor com essa divisão estariam do lado do rendimento todos os aspectos negativos, como a mecanização, a dor, a supremacia da razão perante a emoção e do lado lúdico as virtudes, entre elas, a satisfação, o sentido de liberdade e a criatividade. 
Há que se ter um melhor entendimento sobre a palavra rendimento, pois não se pode puramente atribuí-la como sinônimo de esporte com objetivos vinculados ao alto nível ou ao denominado esporte profissional.

Entende-se haver dois tipos de rendimento, um deles é o rendimento máximo, aquele que está vinculado ao alcance de índices, quebra de marcas e de recordes, este realmente não se encaixa no ambiente escolar, essencialmente no trato da dimensão procedimental, vinculado aos alunos executarem os movimentos com elevado nível de exigência.

Porém, ao direcionar a atenção às dimensões conceituais e atitudinais permite-se sim tratar de aspectos de rendimento do esporte profissional no ambiente escolar, como por exemplo, promover a discussão da relação de atletas de alto nível e saúde; o uso de anabolizantes para melhora de resultados; as diferenças de objetivos ao se praticar modalidades esportivas em cenários diferentes, como o basquetebol da NBA (instituição que organiza o campeonato nacional de clubes nos Estados Unidos) e o basquetebol que o aluno jogará na praça pública; os eventos dos quais as seleções brasileiras de voleibol participam e a vivência dessa modalidade no âmbito escolar; entre outros.

No aspecto atitudinal pode-se abordar a violência em estádios de futebol, tanto entre as torcidas, como em casos de agressóes entre os próprios jogadores; a questão do "fair-play" - será que ele realmente acontece no esporte profissional ou apenas é uma fachada?

Destaca-se com isso que no âmbito da dimensão procedimental o esporte com metas de rendimento máximo realmente não se enquadra na Educação Física escolar, entretanto ele pode ser abordado nas dimensões conceitual e atitudinal.

Todavia, há também o rendimento ótimo, este sim pode estar presente totalmente nas aulas de Educação Física. Esse rendimento caracteriza-se pela busca da aprendizagem na maior qualidade possível, obviamente sendo específico para cada aluno.

COSTA e NASCIMENTO (2004) também reforçam a busca pelo rendimento ótimo nas aulas de Educação Física escolar. Os autores salientam que este tipo de rendimento não se caracteriza pela relação do esporte com o alto rendimento, mas sim, com o propósito de almejar a evolução na aprendizagem do aluno.

\section{Categoria: dimensões do conteúdo}

Ocorreu uma atenção especial com essa categoria, pois as dimensões do conteúdo é o foco central deste estudo. Verificou-se inicialmente qual o conhecimento dos professores sobre esses termos, se eles utilizavam nas suas aulas as três dimensões do conteúdo e quais as possibilidades de aplicação destas na prática pedagógica durante a realização da pesquisa.

Ao perguntar aos professores se já trabalham com o voleibol nas suas aulas, todos afirmaram já desenvolverem essa modalidade. Ao solicitar posteriormente, o exemplo de uma aula referente a esse conteúdo, observamos por parte da Professora $2 \mathrm{um}$ ensino com a utilização do método tradicional, no qual há o trabalho isoladamente dos fundamentos para em um segundo momento ocorrer o jogo. "[...] eles tinham a necessidade de toda aula jogar, porque eles não têm a consciência de que primeiro a gente inicia de um processo mínimo pra chegar à conclusão de poder desenvolver o jogo" (Professora 2).

Não somos radicalmente contra o método que se preocupa com a qualidade dos gestos motores, todavia, concordamos com BAYER (1994), GraçA (1998) e GARGANTA (1998) quando apontam para a iniciação de modalidades coletivas pelo jogo, como também, especificamente no caso do voleibol, "jogo reduzido" defendido por MesquiTa (1998), "modelo de abordagem progressiva ao jogo" em MESQUTTA (2006) e "ensinando jogos para compreensão" de SouzA (1999).

A Professora 1 admitiu ter um certo incômodo ao ensinar voleibol no ambiente escolar por interpretar que a modalidade se mostra difícil para aprendizagem. Relatou que vem trabalhando na perspectiva do jogo possível, defendido por PAEs (2002).

Então o que eu fiz com as turmas do ano passado, através do jogo de pega, do jogo da queimada, do mesmo câmbio, entrar com os fundamentos dentro do jogo, ao invés de fazer quatro colunas, agora vocês vão daqui até o final da quadra fazendo toque. Eu achei que a resposta foi melhor, [...] (Professora 1).

Observou-se com a Professora 1, a utilização de jogos para o ensino do voleibol, com os fundamentos sendo trabalhados no contexto de vários tipos de jogos, porém o ensino continua contemplando apenas os aspectos procedimentais.

Em relação à Professora 3, percebeu-se uma preocupação em romper a barreira do apenas realizar movimentos, quando se propôs a trabalhar outros aspectos referentes ao voleibol. "Antes de começar o vôlei mesmo, eu falei sobre "minonette", mostrei pra eles como era a quadra antes, como que é agora, mostrei as diferenças, as evoluçôes do voleibol e da história” (Professora 3).

Há uma contextualização da Professora ao verificar com os alunos a origem, a trajetória da modalidade, as suas alteraçôes e evoluções; dessa 
forma, baseado em DARIDO (2004) verifica-se uma atenção quanto à dimensão conceitual.

Com o desenvolvimento dos encontros, por meio de leituras solicitadas pelo professor pesquisador e das discussões efetuadas nas reuniōes houve um melhor entendimento da conceituação das três dimensōes do conteúdo, com isso se tornou possível a elaboração de atividades que as envolvessem.

Durante as discussões sobre a conceituação do termo conteúdo, tendo como referências ZaBALA (1998) e Coll et al. (2000), a Professora 3 mostrouse preocupada em oferecer um ensino no qual houvesse uma aprendizagem de qualidade por parte dos alunos, conforme observado:

Eu percebi que mesmo eu já tendo explicado pra eles a história do voleibol, tentado na prática, ainda tem uma dificuldade muito grande, que eles não tavam entendendo algumas coisas. Aí eu falei, poxa, preciso arrumar um jeito que eles se interessem mais, que cada um gosta de uma coisa diferente. Tem gente que gosta da prática, tem gente que gosta mais da teoria (Professora 3).

Nessa perspectiva teve a ideia de trabalhar o mesmo assunto, a história do voleibol, com a estruturação de um teatro, havendo a participação de professores de outros componentes curriculares, conforme citado na categoria condiçóes de trabalho.

A Professora 1 posicionou-se em relação à importância da realização de uma interação entre os aspectos procedimentais com os conceituais e atitudinais. Este posicionamento nos remete a DARIDO e RANGEL (2005), pois conforme as autoras na Educação Física há uma predominância de se trabalhar os procedimentos e não abranger as demais dimensôes.

$\mathrm{Eu}$ acho que tem a ver também, que os professores não fazem a ponte. Às vezes, eu tenho a impressão assim, tá lá na quadra, fez tá bom. Se você não resgatar aquilo em outros momentos, na sala, com textos, vídeos, morre ali na quadra. $\mathrm{O}$ bater o sinal e ir pra classe põe um fim naquilo (Professora 1).

Segundo DARIDO (2004) durante várias atividades das aulas de Educação Física estão intrínsecos temas referentes aos valores e às atitudes, porém manifestando-se apenas no chamado currículo oculto. Viu-se a necessidade de ter uma melhor estruturação de tais assuntos, pois caso contrário, não se explora de forma adequada, havendo pouca assimilação por parte dos alunos.

Quando foi discutido especificamente o ensino do voleibol nas três dimensões do conteúdo, o Professor 4 questionou como poderia fazer essa abordagem dando ênfase, em certos momentos, à dimensão conceitual, sem haver desmotivação por parte dos alunos. Obtiveram-se as seguintes respostas das Professoras: "Você é que tem que intermediar sua turma. Se você acha que a turma tá empolgada naquele debate, você vai naquela parte, você puxa. Senão, você tá achando que tá caindo, aí você já muda" (Professora 1).

Mas, eu acho que se você ficar muito tempo só em sala de aula também, eu acho que você sai do foco, eu acho que você tem que ponderar, eu acho que você tem o momento da teoria, tem a hora da quadra, mesmo porque você pode trabalhar a teoria na quadra (Professora 3 ).

Percebeu-se principalmente por parte da Professora 3 um bom entendimento da proposta, procurando sinalizar caminhos para o desenvolvimento dos trabalhos. Assim, pode-se referir a BETTI (2001) quando chama a atenção para o fato de a ideia não ser a transformação das aulas de Educação Física em teóricas, mas sim incluir a reflexão nas atividades apresentadas pelos professores.

Mostra-se importante destacar o exemplo de uma atividade mencionada pela Professora 3:

Eu tava falando sobre a mudança dos pisos. Os alunos queriam saber por que mudou. Eu falei, gente, olha a altura dos jogadores de voleibol. $\mathrm{O}$ que eu peguei? Eu peguei a cadeira, subi na cadeira e fiquei super alta. Do jeito que eu tava alta, eu falei, olha só, agora eu vou saltar e vou cair. Eu saltava e caia, pra eles verem o impacto que tava tendo. Vocês imaginem o joelho dos jogadores, tornozelo, quantas lesões iriam acontecer? Aí eles quiseram fazer a mesma coisa na sala de aula e eu deixei. Eu deixei que eles subissem na cadeira e saltassem.

Nesse exemplo observa-se o assunto pertencente à dimensão conceitual, tratando da evolução tecnológica para os jogos de voleibol, inter-relacionado com a dimensão procedimental, pois os alunos não só ouviram a explicação da Professora, mas também puderam executar o movimento para uma melhor assimilação do que estava sendo tratado. Existem dois aspectos importantes neste episódio, o primeiro refere-se ao posicionamento de DARIDO (2004), no qual a separação das dimensões deve acontecer somente em termos de planejamento, pois na prática pedagógica do professor precisam estar interligadas. O segundo tem a ver com o que Coll et al. (2000) denominam de aprendizagem significativa, na qual o professor proporciona ao aluno um significado naquilo que está sendo desenvolvido. Nessa atividade apresentada pela Professora 3 o fato de os alunos poderem subir na cadeira e executarem o salto propiciou uma interiorização daquele conhecimento, pois os alunos sentiram as dificuldades referentes ao amortecimento do salto. 
Ao perguntar aos professores participantes da pesquisa sobre as possibilidades de se trabalhar com essa proposta, obteve-se respostas determinantes:

[...] eu acho que o meu trabalho ficou bem mais estruturado dessa forma, porque eu sempre achei que o vôlei era um empecilho, o como eu vou ensinar uma modalidade que exige muito da habilidade, então dessa forma que vocês ajudaram a construir, eu achei que ficou muito melhor (Professora 1).

[...] aula diferente, aula mais dinâmica pros alunos, sai daquela rotina chega na quadra joga vôlei ou joga futebol. O tipo de aula que aconteceu permite uma interação maior entre o grupo todo, porque as salas lá onde eu trabalho eles não conhecem todos os alunos, tem 35 , eles não se conhecem, eles não sabem o nome de todos os colegas (Professora 2).

Eu acho que foi uma maneira diferente da gente trabalhar o conteúdo, eu conheci um pouco das partes, a gente conversou bastante na faculdade, mas em relação à maneira de trabalhar, como o jogo da memória que eu fiz, a maquete, eles nunca tinham feito a maquete na vida, então, saíram maquetes bem legais, maquetes bem bacanas (Professor 4).

Os posicionamentos dos professores 1, 2 e 4 foram muito positivos, pois eles não abordavam ou trabalhavam pouco nas suas respectivas práticas pedagógicas assuntos referentes à dimensão conceitual e atitudinal.

Apresenta-se ainda mais satisfatório o fato de terem ido além da modalidade esportiva voleibol. Ao questionar os professores sobre as possibilidades de trabalhar as três dimensões em outros conteúdos da Educação Física escolar e solicitar exemplos, obteve-se as seguintes respostas:

Eu acho que sim, tanto na dança, como na ginástica, eu acho que todos. Todos são possíveis de aplicar. Eu acho que é mais uma questão de quebra de tabu mesmo, aquilo que a gente já tinha falado, não é só quadra, tem o momento da discussão, tem o momento da pesquisa (Professora 1).

Eu acho que é possível desde que tenha ajuda da escola. Acho que a escola tem um papel fundamental. Porque às vezes a gente quer tá trabalhando com o aluno alguma coisa diferente e não tem uma aceitação assim por parte dos professores e da direção. Eu acho que se eles apóiam, se eles ajudam é possível qualquer conteúdo (Professora 3).
Percebeu-se que os quatro professores envolvidos na pesquisa demonstraram um bom entendimento da aplicação das três dimensões no ensino da modalidade esportiva voleibol e puderam fazer relações com outros conteúdos da cultura corporal de movimento. Entretanto, as Professoras 1 e 3 foram as que mais demonstraram avanço, entende-se que isso se deu pelo fato de a Professora 3 já apresentar um prévio conhecimento do assunto e trabalhar nessa perspectiva e de a Professora 1 ter maior tempo de experiência na área de trabalho, ter cursado uma especialização em Educação Física escolar, participar de grupos de estudos, cursar disciplinas da pós-graduação como aluna especial - tudo isso favorecendo para um melhor entendimento da proposta.

\section{Categoria: alunos - características, expectativas e participação}

Esta categoria apresenta-se como fundamental para este estudo, pois toda pesquisa com a organização dos trabalhos, a estruturação dos encontros com o grupo de professores, a elaboração e aplicação das aulas, converge para a mesma direção, propiciar um ensino de melhor qualidade aos alunos.

Os professores participantes da pesquisa ao serem questionados no primeiro encontro sobre as dificuldades para ministrarem as aulas foram unânimes em afirmar a questão da indisciplina; os professores 2, 3 e 4 ainda destacaram a insistência dos alunos para a prática do futebol.

A questão da indisciplina dos alunos não é uma novidade na queixa dos professores de diversos componentes curriculares e o jogar futebol está relacionado com uma Educação Física que em muitos locais não apresenta uma organização dos conteúdos a serem trabalhados, tendo os alunos basicamente tempo livre para escolha do que realizar.

DARIDO (2005) entende que existem razões para os alunos constantemente solicitarem a prática do futebol, primeiro pela questão da mídia destinar um tempo extremamente superior ao futebol em relação às demais práticas, e segundo pelo fato de haver uma cultura escolar na qual há predominância do ensino do futebol. Sendo assim, os alunos, de antemão, aguardam pela prática dessa modalidade esportiva.

Apesar de os alunos demonstrarem resistência no primeiro momento, por meio da estruturação das aulas, da organização dos conteúdos e da diversificação de estratégias, os mesmos responderam positivamente, apresentando bom envolvimento durante a aplicação das aulas referentes ao conteúdo voleibol. Dessa forma percebeu-se um aumento de 
interesse na proposta de trabalho desenvolvida, com posicionamentos interessantes, estimulando a criatividade e uma melhora na aprendizagem, conforme pode-se observar no relato da Professora 3:

Um aluno da quinta série $B$, ele falou assim: nossa dona, por incrível que pareça dá pra gente trabalhar tudo, em todas as disciplinas, né? Porque eu nunca imaginei que, com voleibol, a gente poderia tá pedindo informação pro professor de português, de história, de geografia.

Houve o envolvimento dos alunos da Professora 3 durante a preparação e apresentação do teatro. Pode-se observar, com o acompanhamento das aulas do professor pesquisador, atividades de ensaio dos alunos para a apresentação e a aula da apresentação, constatando-se uma participação efetiva dos alunos na proposta idealizada pela Professora.

De uma maneira geral os alunos não apresentaram resistência, ao contrário, estavam compromissados e preocupados com a data da apresentação que estava por chegar, mesmo aqueles considerados indisciplinados pela Professora estavam cumprindo os seus deveres, apenas com a necessidade em certos momentos da interferência da Professora para a retomada da atividade. Os únicos que tiveram uma resistência maior foram os alunos com a idade mais avançada, cerca de três a quatro anos mais velhos que a faixa etária média da turma, devido às reprovações. Esses alunos questionaram a Professora sobre o porquê desse tipo de atividade e ela explicou que fazia parte do seu planejamento para a $5^{\text {a }}$ série, sendo que, com as séries mais adiantadas desenvolvia outros conteúdos.

Obviamente os resultados não foram os mesmos em todas as salas, pois cada uma tinha as suas características, facilidades e dificuldades. Verificou-se um bom desenvolvimento dos trabalhos apresentados, porém, em determinadas turmas houve uma maior estruturação com melhor desempenho tanto no conteúdo, como na forma de apresentação. Isso não é um problema, pois cada turma vai apresentar um determinado ritmo de trabalho na Educação Física e nos demais componentes curriculares.

Destacam-se outros posicionamentos dos professores, em relação à participação e à aprendizagem dos alunos:

Eles tão encarando o tema vôlei de uma forma diferente do que eu esperava. Eu achei que eles fossem boicotar. Mas a resposta tá sendo muito positiva, muito positiva mesmo. [...] eu já tinha trabalhado com sextas séries antes, já tinha tentado ensinar vôlei antes e não achava o caminho. Eu achei que o retorno dessa sala foi bem bacana, tá sendo bem bacana (Professora 1).
[...] eles não tão acostumados a trabalhar com aquele ritmo de aula, é o que eu falei pra você, acostumado só com jogo só, prática só. Até um dia que eu dei o jogo da memória, eles ficaram encantados, porque chegou na quadra tinha um monte de peça espalhada no meio na quadra, eles falaram: mas o que que é isso? Que aula é essa? A gente vai jogar vôlei, não vai, o que vai acontecer? Eu falei, olha vai ter um jogo hoje, vai ter uma gincana entre meninos e meninas, eu fiz a gincana. E aí o pessoal começou, eu quero tal peça e tal peça, aí o pessoal começou ver que as peças tinham muito a ver com o voleibol e daí eles começaram a se envolver mais (Professor 4).

Eu acho que a aula do jeito que foi promovida promoveu uma interação maior entre os alunos, foi bacana pra eles. Exploração da criatividade deles foi excelente. [...] eles fizeram cartazes, muito bacana, fizeram a pesquisa, eles foram atrás. Eu acho que eles ficaram muito mais interessados com as aulas desse jeito (Professora 2).

Um ponto rico no estudo foi a possibilidade do professor pesquisador aplicar oito aulas juntamente com a Professora 2, em uma turma de $6^{a}$ série. $\mathrm{Na}$ primeira aula a turma mostrou-se dispersa, tendo momentos curtos de concentração. Mesmo com a baixa atenção os alunos participaram bem das atividades em sala de aula e ninguém se opôs a realizá-las.

Do primeiro para o segundo encontro com os alunos solicitou-se a realização de uma entrevista com seus pais ou outros parentes mais velhos. Obteve-se um resultado positivo, pois cerca de $70 \%$ da turma realizou a atividade. Com isso, pode-se discutir as alteraçōes das regras do voleibol e o porquê de elas ocorrerem. Mesmo na sala de aula houve uma maior concentração dos alunos, melhora considerável em relação ao primeiro encontro, com eles perguntando, apresentando as respostas da pesquisa, discutindo e posicionando-se.

Com o dvd foi exibida uma reportagem sobre o voleibol sentado (voleibol para deficientes físicos). Foi surpreendente o nível de concentração e envolvimento dos alunos nesse dia, fazendo comentários e demonstrando curiosidade pelo conteúdo trabalhado. Ao chegarem na quadra foi realizado o minivôlei ou voleibol reduzido, proposta defendida por MESQUITA $(1998,2006)$ para o processo de ensino e aprendizagem do voleibol. Utilizando a única bola de voleibol existente na escola e bolas de borracha. O único material usado, que não pertencia à escola, foi uma fita elástica, material barato e de fácil aquisição. Outro 
fator positivo nesse dia foi a participação de todos os alunos nos jogos; mesmo duas alunas que ficaram fora de atividades em aulas anteriores interagiram com o grupo. Durante os jogos alguns alunos reclamaram dos erros de seus colegas. O professor pesquisador e a Professora 2 procuraram relacionar esse fato com o que foi visto e discutido anteriormente durante a exibição do dvd abordando as atitudes das pessoas.

No último encontro realizou-se o jogo adaptado (jogo de câmbio com variaçôes), utilizando a pontuação com e sem a vantagem. Foi significativo observar os alunos, que não estavam jogando naquele momento, concentrados na marcação dos pontos, podendo analisar e posteriormente discutir com maior evidência as duas formas diferentes de pontuação.

Ao perguntar aos professores participantes quanto ao posicionamento dos alunos sobre a proposta de aplicação das aulas abordando as três dimensões do conteúdo obteve-se respostas significativas, por exemplo, a turma da Professora
2: "Lá eles adoraram. Eles falam o tempo todo, eles perguntam, eles comentam o que eles aprenderam, o que eles perceberam com as atividades que a gente desenvolveu. Eles gostaram do que a gente trabalhou o tempo todo eles comentam eles falam".

Chamou a atenção o posicionamento de alguns alunos do professor 4: "Os alunos perguntaram: por que você não falou da trajetória das regras do handebol? Por que não foi assim também? E do basquete? Você não falou! Por que só do voleibol?”.

Esse comentário reforça a ideia de que mesmo os alunos estando acostumados com as aulas de Educação Física apenas relacionadas a aprender a realizar movimentos esportivos ou querendo somente a prática do futebol, quando se estrutura o trabalho, aplicam-se estratégias diversificadas, ampliam-se as possibilidades de envolvimento dos alunos e abordam-se aspectos relacionados ao entendimento mais amplo do conteúdo, existe uma grande possibilidade de motivação e interesse por parte dos alunos.

\section{Considerações finais}

Teve-se o objetivo neste estudo de construir, implementar e avaliar uma proposta de ensino do voleibol nas três dimensões do conteúdo: conceitual, procedimental e atitudinal.

Foram analisadas, a partir dos dados obtidos, as condiçóes de trabalho, por que e para que ensinar esporte (voleibol), técnica esportiva e rendimento, dimensões do conteúdo e características, expectativas e participação dos alunos. Ressalta-se ainda, o fato de essas categorias, em vários momentos, não aparecem isoladamente, existindo uma interrelação entre as mesmas. Principalmente a categoria dimensões do conteúdo possibilitou a realização de inter-relações com as demais categorias, fazendo com que as discussóes envolvendo conceitos, procedimentos e atitudes permeassem vários momentos dos encontros. Pode-se destacar alguns itens em que foi feito um paralelo com as três dimensões: a utilização de espaços variados durante a aplicação das aulas; o envolvimento de professores de outras áreas de conhecimento no projeto interdisciplinar desenvolvido pela Professora 3; a ideia de participação na amostra cultural na escola do professor 4; a discussão envolvendo técnica esportiva e as metodologias para o ensino do voleibol.

É importante ressaltar as expectativas dos professores no início dos encontros e a avaliação que

realizaram sobre o desenvolvimento dos trabalhos. Ao serem questionados no primeiro encontro sobre qual o tipo de produção seria interessante para utilizarem na prática pedagógica, referiram-se à possibilidade de conhecer novas atividades que tornem a aula mais interessante para os alunos. Em contrapartida, uma professora posicionouse alertando para não ficarmos apenas na pura elaboração de atividades, mas sim nos preocuparmos em promover o desenvolvimento das aulas havendo heterogeneidade no grupo de alunos, apresentando características como aluno repetente, aluno que deixa de fazer a atividade no meio ou mesmo se recusa a realizar qualquer tipo de tarefa.

O retorno apresentado pelos professores no último encontro foi positivo, quando questionados se o estudo contemplou as expectativas e sobre a avaliação desta pesquisa. Além da elaboração de atividades, destacam-se alguns apontamentos dos professores: possibilitou entrar em contato com realidades diferentes; garantiu novas aprendizagens; mostrou a importância da discussão em grupo para o crescimento profissional; propiciou a reavaliação da sua própria prática pedagógica; favoreceu a estruturação e a aplicação das aulas; proporcionou a transposição da dificuldade de ensinar o voleibol; possibilitou vencer o desafio de se trabalhar com 
uma nova proposta; propiciou um ensino de qualidade para os alunos mais habilidosos e os menos habilidosos; garantiu maior envolvimento dos alunos durante as aulas; proporcionou o comprometimento do pesquisador e dos professores participantes com o trabalho; facilitou o oferecimento ao aluno da aprendizagem da modalidade voleibol, abrangendo não só o ensino dos movimentos, mas também os aspectos relacionados aos conceitos, valores e atitudes; ofereceu a possibilidade de utilizar o conhecimento adquirido neste estudo para a futura prática profissional.

Apesar dos fatores favoráveis mencionados pelos professores, pode-se relacionar alguns pontos que em determinadas ocasiōes apresentaram-se como dificuldades: a discriminação dos professores de outras áreas perante a Educação Física, a indisciplina por parte dos alunos, a resistência dos alunos para a realização de atividades que não envolvessem a prática do futebol, uma desmotivação por parte dos alunos que apresentavam idade superior à faixa etária média da turma.

É importante ressaltar que os resultados desta pesquisa contou essencialmente com o compromisso assumido pelos professores participantes. É verdade que em alguns encontros ocorreram certas ausências devido a compromissos assumidos. Mas o envolvimento com o trabalho, o cumprimento das solicitações, a predisposição para participar das reuniōes aos sábados pela manhã e em dias da semana à noite, a abertura para o pesquisador assistir e aplicar aulas, a honestidade e a sinceridade demonstradas foram fatores fundamentais para o bom desenvolvimento deste estudo.

Foi notório que o trabalho ofereceu a todos os professores participantes, inclusive ao pesquisador, um enriquecimento no conhecimento referente à Educação Física escolar. Porém, salienta-se que os resultados desta pesquisa não necessariamente podem ocorrer com outros professores, pois é importante destacar as características do grupo participante do trabalho, apresentando o interesse pela busca de novos conhecimentos e uma contínua formação na área de atuação profissional.

Constatou-se uma participação efetiva dos alunos nas aulas, inclusive quando as atividades não tinham como referência exclusiva a execução de movimentos esportivos, mas isso somente se deu pela disposição dos professores em estruturarem de forma apropriada as suas aulas, estudando, destinando tempo para elaboração das atividades e oferecendo estratégias diversificadas que estimulassem o envolvimento dos alunos.

\begin{abstract}
School volleyball: a proposal to teaching in the dimensions concept, procedure and attitude of content

The objective of this study was to build, implement and evaluate a proposal to teaching of volleyball in the three dimensions of content: concept, procedure and attitude. For the development of the present work it was used the method of search-action. Eight meetings were held with the participation of four teachers. The results obtained were discussed in the perspective of working conditions, in the reasons and contents of teaching the sport (volleyball), technology and sports performance, in the dimensions of the content and features, expectations and participation of students. It was found that, in some schools, the working conditions, in relation to the physical space, the available material, the under evaluation of the Physical Education or even the suspicion of other teachers and supervisors, present themselves as obstacles to the development of this component curriculum. However, it was observed that the teachers participating successfully develop a quality education, contributing to rebuilding importance of Physical Education in the environment of formal education. It was confirmed the possibility of developing contents that may go beyond procedure dimension, facilitating the approach of the dimensions concept and attitude of volleyball. Moreover, it was for the effective participation of students, but it has only been due to the provision of teachers in structuring as appropriate their classes, studying, intended time for preparation of activities and offering diverse strategies that stimulated the involvement of students.
\end{abstract}

UnITERMs: Physical education; School; Pedagogy of sports; Search-action; Volleyball. 


\section{Nota}

1. O grupo do LETPEF é vinculado ao Departamento de Educação Física do Instituto de Biociências da UNESP/Rio Claro, tendo como membros professores de Educação Física, sendo coordenado pela professora Suraya Cristina Darido.

\section{Referências}

ANDRÉ, M.E.D.A. Etnografia da prática escolar. Campinas: Papirus, 1995.

BAYER, C. O ensino dos jogos desportivos colectivos. Paris: Vigot, 1994.

BETTI, M. Educação física e sociedade. São Paulo: Movimento, 1991.

. Educação física, esporte e cidadania. Revista Brasileira de Ciências do Esporte, Campinas, v.20, n.2/3. p.84-92, 1999. . Mídias: aliadas ou inimigas da educação física escolar? Motriz, Rio Claro, v.7, n.2. p.125-9, 2001.

BIZZOCCHI, C.E. Voleibol de alto nível: da iniciação à competição. São Paulo: Manole, 2004.

BOJIKIAN, J.C.M. Ensinando voleibol. 2. ed. São Paulo: Phorte, 2003.

BRACHT, V. Esporte na escola e esporte de rendimento. Revista Movimento, Porto Alegre, v.4, n.12, p.14-29, 2000/2001. BRACHT, V.; CAPARROZ, F.E.; DELLA FONTE, S.S.; FRADE, J.C.; PAIVA, F.; PIRES, R. Pesquisa em ação: educação física na escola. Ijuí: Unijuí, 2003.

BRASIL. Secretaria de Educação Física. Parâmetros curriculares nacionais: educação física. Brasília: MEC/SEF, 1998. CAMPOS, L.A.S. Voleibol “da” escola. Jundiaí: Fontoura, 2006.

COLL, C.; POZO, J.I.; SARABIA, B.; VALLS, E. Os conteúdos na reforma: ensino e aprendizagem de conceitos, procedimentos e atitudes. Porto Alegre: Artmed, 2000.

COSTA, L.C.A.; NASCIMENTO, J.V. O ensino da técnica e da tática: novas abordagens metodológicas. Revista da Educação Física/UEM, Maringá, v.15, n.2, p.49-56, 2004.

COVRE, M.L.M. O que é cidadania. 8. reimp. São Paulo: Brasiliense, 1999.

DARIDO, S.C. Educação física escolar: o conteúdo e suas dimensões. In: DARIDO, S.C.; MAITINO, E.M. (Orgs.). Pedagogia cidadã: cadernos de formação - educação física. São Paulo: UNESP/Pró-reitoria de Graduação, 2004. p.59-70. Educação física na escola: a experiência de uma professora universitária no contexto escolar. In: UNIVERSIDADE

FEDERAL DO RIO GRANDE DO NORTE. Coleção cotidiano escolar: a educação física no ensino fundamental (5a a 8a séries). Natal: Paidéia, 2005. p.23-31.

DARIDO, S.C.; RANGEL, I.C.A. (Coords.). Educação física na escola. Rio de Janeiro: Guanabara Koogan, 2005.

GALVÃO, Z.; RODRIGUES, L.H.; SANCHES NETO, L. Cultura corporal de movimento. In: DARIDO, S.C.; RANGEL, I.C.A. (Coords.). Educação física na escola. Rio de Janeiro: Guanabara Koogan, 2005. p.25-36.

GARGANTA, J. Para uma teoria dos jogos desportivos colectivos. In: GRAÇA, A.; OLIVEIRA, J. (Eds.). O ensino dos jogos desportivos. 3. ed. Lisboa: Universidade do Porto, 1998. p.11-25.

GRAÇA, A. Os comos e os quandos no ensino dos jogos. In: GRAÇA, A.; OLIVEIRA, J. (Eds.). O ensino dos jogos desportivos. 3. ed. Lisboa: Universidade do Porto, 1998. p.27-34.

KORSAKAS, P.O. Esporte infantil: as possibilidades de uma prática educativa. In: De ROSE JUNIOR, D. et al. Esporte e atividade física na infância e na adolescência. Porto Alegre: Artmed, 2002. p.39-49.

LEMOS, A.S. Voleibol escolar. Rio de Janeiro: Sprint, 2004.

MAUSS, M. Noção de técnica corporal. In: MAUSS, M. Sociologia e antropologia. São Paulo: EPU/EDUSP, 1974. v.2, p.211-33. MESQUITA, I. O ensino do voleibol: proposta metodológica. In: GRAÇA, A.; OLIVEIRA, J. (Eds.). O ensino dos jogos desportivos. 3. ed. Lisboa: Universidade do Porto, 1998. p.153-99.

. Ensinar bem para aprender melhor o jogo de voleibol. In: TANI, G.; BENTO, J.O.; PETERSEN, R.D.S. Pedagogia do desporto. Rio de Janeiro: Guanabara Koogan, 2006. p.327-44.

PAES, R.R. A pedagogia do esporte e os jogos coletivos. In: De ROSE JUNIOR, D. et al. Esporte e atividade física na infância e na adolescência. Porto Alegre: Artmed, 2002. p.89-98.

. Pedagogia do esporte: especialização esportiva precoce. In: TANI, G.; BENTO, J.O.; PETERSEN, R.D.S. Pedagogia do desporto. Rio de Janeiro: Guanabara Koogan, 2006. p.219-26.

PALMA FILHO, J.C. Cidadania e educação. Caderno de Pesquisa, São Paulo, n.104. p.101-21, 1998.

PINSKY, J. Pensando o Brasil. In: PINSKY, J. Cidadania e educação. 5. ed. São Paulo: Contexto, 2001. p.15-38. 
QUADROS JÚNIOR, P.K.; QUADROS, T.M.B.; GORDIA, A.P. Proposta metodológica para o mini-voleibol: uma estratégia para iniciação esportiva de crianças. Lecturas, Educación Física y Deportes: Revista Digital, Buenos Aires, v.12, n.110, 2007.

RODRIGUES, H.A.; DARIDO, S.C. A técnica esportiva em aulas de educação física: um olhar sobre as tendências sócioculturais. Revista Movimento, Porto Alegre, v.14, n.2, p.137-54, 2008.

SOARES, C.L.; TAFFAREL, C.N.Z.; VARJAL, E.; CASTELLANI FILHO, L.; ESCOBAR, M.O.; BRACHT, V. Metodologia do ensino da educação física. São Paulo: Cortez, 1992.

SOUZA, A.J. É jogando que se aprende: o caso do voleibol. In: NISTA-PICCOLO, V.N. (Org.). Pedagogia dos esportes. Campinas: Papirus, 1999. p.79-112.

SOUZA JÚNIOR, O.M. Educação física escolar, co-educação e questões de gênero. In: DARIDO, S.C.; MAITINO, E.M. (Orgs.). Pedagogia cidadã: cadernos de formação - educação física. São Paulo: UNESP/Pró-Reitoria de Graduação, 2004. p. 71-86.

THIOLLENT, M. Metodologia da pesquisa-ação. 12. ed. São Paulo: Cortez, 2003.

TOURAINE, A. Podemos viver juntos? Iguais e diferentes. Petrópolis: Vozes, 1998.

TUBINO, M.J.G. Uma visão paradigmática das perspectivas do esporte para o início do século XXI. In: GEBARA, A.; MOREIRA, W.W. (Orgs.). Educação física \& esportes: perspectivas para o século XXI. 9. ed. Campinas: Papirus, 2002. p.125-39. VENÂNCIO, L. Projeto político-pedagógico e a educação física escolar: uma prática pedagógica possível. In: UNIVERSIDADE FEDERAL DO RIO GRANDE DO NORTE. Coleção cotidiano escolar: a educação física no ensino fundamental (5 a 8 ${ }^{\mathrm{a}}$ séries). Natal: Paidéia, 2005. p.114-27.

YIN, R.K. Estudo de caso: planejamento e método. 2. ed. Porto Alegre: Bookman, 2001.

ZABALA, A. A prática educativa: como ensinar. Porto Alegre: Artmed, 1998.

\begin{tabular}{|c|c|}
\hline $\begin{array}{r}\text { ENDEREÇo } \\
\text { André Luís Rugiero Barroso } \\
\text { R. Dr. José Ramos de Oliveira Júnior, } 425 \\
\text { 13085-751 - Campinas - SP - BRASIL } \\
\text { al.barroso@uol.com.br }\end{array}$ & $\begin{array}{l}\text { Recebido para publicação: 27/03/2009 } \\
\text { 1a. Revisão: 09/09/2009 } \\
\text { 2a. Revisão: 14/10/2009 } \\
\text { Aceito: 15/10/2009 }\end{array}$ \\
\hline
\end{tabular}

194 • Rev. bras. Educ. Fís. Esporte, São Paulo, v.24, n.2, p.179-94, abr./jun. 2010 